\title{
Evolução da salinidade em um Argissolo sob cultivo de melão irrigado por gotejamento ${ }^{1}$
}

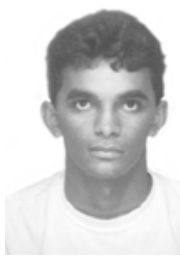

Nildo da S. Dias², José F. de Medeiros ${ }^{3}$, Hans R. Gheyi", Francisco V. da Silva ${ }^{4}$ \& Adilson D. de Barros ${ }^{4}$.

\footnotetext{
${ }^{1}$ Parte da Dissertação de Mestrado do primeiro autor apresentada a UFCG. Pesquisa financiada pelo Programa Avança Brasil-Convênio Embrapa-ESAM.

2 Embrapa MEIO NORTE, CP 01, CEP 64006-220, Teresina, PI. Fone: (86) 225-1141. E-mail: nisdias@cpamn.embrapa.br (Foto)

${ }^{3}$ ESAM, ENA, CP 137, CEP 59625-900, Mossoró, RN. Fone: (84) 321-2100. E-mail: jfmedeir@esam.br

${ }^{4}$ UFCG/CCT/DEAg. CP 10087, CEP 58109-970. Fone: (83) 310-1055. E-mail: hans@deag.ufcg.edu.br
}

Protocolo 6 - 16/1/2002 - Aprovado em 2/4/2004

Resumo: Com objetivo de estudar a evolução da salinidade em Argissolo sob cultivo de melão irrigado por gotejamento com diferentes níveis de salinidade e práticas diferenciadas de manejo de irrigação, desenvolveu-se um experimento na Fazenda São João, Município de Mossoró, RN. Os tratamentos estudados se compunham da combinação de três fatores: salinidade da água de irrigação com 3 níveis $\left(S_{1}-1,2 ; S_{2}-2,5\right.$ e $\left.S_{3}-4,5 d S m^{-1}\right)$, duas cultivares de melão $\left(C_{1}\right.$ - Honey Dew cultivar Orange flesh e $C_{2}$ - Cantaloupe híbrido Trusty) e duas freqüências de irrigação $\left(F_{1}\right.$ intervalos de um dia até os 30 dias após a semeadura (DAS) e duas vezes por dia a partir dos 30 DAS e $F_{2}$ - intervalos de dois dias até os 30 DAS e uma vez por dia, a partir dos 30 DAS). 0 delineamento estatístico adotado foi o de blocos casualizados completos com 4 repetições e os fatores estudados foram arranjados no esquema fatorial de $3 \times 2 \times 2$. Avaliou-se a evolução da salinidade do solo usando-se o método padrão, com uso de extratores. Os resultados mostraram que a salinidade do solo evoluiu com o tempo, estando os maiores níveis próximos de superfície do solo; a salinidade do solo atingiu o máximo na fase intermediária, tendendo a reduzir no final do ciclo do meloeiro; a evolução da salinidade do solo foi proporcional à concentração de sais na água de irrigação, independente da freqüência de irrigação. A salinidade medida com o extrator e corrigida pela umidade atual do solo foi equivalente à salinidade determinada pelo método padrão.

Palavras-chave: condutividade elétrica, manejo de água, Cucumis melo L.

\section{Evolution of salinity in Luvissol under drip irrigated melon}

\begin{abstract}
A study was carried out at "São João" Farm to evaluate the evolution of soil salinity under drip irrigated melon crop, using different water salinity levels and irrigation management in the municipality of Mossoró-RN. The treatments were composed of combination of three factors consisting of three levels of water salinity $\left(\mathrm{S}_{1}-1.2, \mathrm{~S}_{2}-2.5\right.$ and $\left.\mathrm{S}_{3}-4.5 \mathrm{dS} \mathrm{m}^{-1}\right)$, two cultivars of melon $\left(C_{1}\right.$ - Honey Dew cultivar Orange flesh and $C_{2}$ - cantaloupe hybrid Trusty) and two frequencies of irrigation ( $F_{1}$ - intervals of one day up to 30 days after sowing (DAS) and thereafler twice a day and $F_{2}$ - interval of two days up to 30 DAS and thereafler daily). The experiment was conducted in a randomized block design, with four replications, arranged in $3 \times 2 \times 2$ factorial scheme. The evolution of soil salinity was evaluated using conventinal and soil solution extraction methods. Results showed that soil salinity increased with time, higher salinity levels being observed near to the soil surface and drippers. Soil salinity tended to attain equilibrium towards the end of the melon crop and that the evolution of the soil salinity was proportional to salt concentration of the irrigation water independent of the irrigation frequency. The salinity observed in soil solution extraction method after correction for moisture content was comparable to salinity determined by conventional method.
\end{abstract}

Key words: electrical conductivity, water management, Cucumis melo L. 


\section{INTRODUÇÃO}

O meloeiro é uma cultura exigente em temperaturas noturnas e diurnas elevadas durante todo o seu ciclo de cultivo. Altas temperaturas e baixa umidade do ar elevam consideravelmente o teor de açúcares nos melões, tornando-os mais saborosos e aromáticos, consistentes e com maior vida útil pós-colheita. Tais características justificam o sucesso da cultura em regiões de climas quentes, como a região Nordeste, especificamente no Estado do Rio Grande do Norte (Negreiros et al., 2003).

Por outro lado e devido à escassez de chuvas nessas regiões, a prática de irrigação constitui uma das alternativas fundamentais para garantir a produção das áreas cultivadas; no entanto, quando não se tem um manejo adequado da irrigação, pode ocorrer a salinização do solo, tornando-o improdutivo em curto espaço de tempo (Oliveira, 1997). Este problema ocorre em quase todos os perímetros irrigados do Nordeste; estima-se que cerca de 25 a $30 \%$ das áreas dos perímetros irrigados do DNOCS estejam salinizados (DNOCS, 1991).

No Estado do Rio Grande do Norte, a água utilizada para irrigação, na região produtora de melão, provém de poços artesianos profundos que, embora de boa qualidade, apresenta alto custo de obtenção, o que impossibilita o seu uso por grande parte dos produtores e os fazem buscar fontes alternativas de água, como poços abertos no calcário Jandaíra, reduzindo consideravelmente seu custo; entretanto, esta fonte de água tem o inconveniente de apresentar níveis elevados de sais, podendo trazer, como conseqüência, a salinização dos solos, além de prejudicar o rendimento das culturas mais sensíveis; além disso, devido à elevada concentração de bicarbonato de cálcio na água (Medeiros et al., 2003) pode tornar o solo alcalino.

Desta forma, o uso de água na irrigação, enquanto contribui de maneira significativa para o aumento da produtividade, em determinadas situações, sobretudo em zonas de clima árido e semi-árido, pode resultar em acúmulo do teor de sais no solo. O excesso de sais no solo reduz a disponibilidade de água para as plantas, além de trazer problemas como o efeito de íons tóxicos específicos sobre a fisiologia vegetal, a tal ponto de afetar seu rendimento e a qualidade de sua produção (Dias et al., 2003).

A prática de irrigação deve ser usada de forma racional, uma vez que as condições de clima do Nordeste (altas temperaturas e baixa pluviosidade) e os elevados teores de sais nas águas de irrigação, têm causado problemas de salinidade nos solos. De acordo com Medeiros \& Gheyi (1997) o nível de salinidade dos solos deve ser sempre inferior ao nível nocivo às plantas cultivadas; assim, o monitoramento direto da salinidade na zona radicular é recomendado para avaliar a eficiência dos diversos programas de manejo nas áreas irrigadas.

A salinidade do solo pode ser determinada a partir de medidas de condutividade elétrica do extrato de saturação $\left(\mathrm{CE}_{\mathrm{es}}\right)$, considerado método padrão, ou da condutividade do extrato em diferentes relações solo:água (Richards, 1954). Em campo, vários métodos são disponíveis para determinar e avaliar a salinidade, como técnica de indução eletromagnética, "fourelectrode probes", "time domain reflectometry-TDR" (Rhoades,
1994) e, ainda, mediante o uso de extratores (Silva, 2002). Cada um desses métodos apresenta vantagens e desvantagens, sendo que o uso de extratores é, atualmente, o mais recomendado, uma vez que a condutividade elétrica (CE) obtida por este método reflete as condições reais em que a planta se desenvolve, de vez que a salinidade média da água contida na zona radicular $\left(\mathrm{CE}_{z \mathrm{zr}}\right)$ é a que deve ser tolerada pelas plantas (Ayers \& Westcot, 1991).

Levando-se em consideração esses aspectos objetivou-se, neste trabalho, estudar a evolução da salinidade em um Argissolo sob cultivo de melão irrigado com águas de diferentes salinidades e práticas diferenciadas de manejo da irrigação, bem como avaliar o uso de extratores na determinação da salinidade do solo.

\section{MATERIAL E MÉTODOS}

O experimento foi desenvolvido na área experimental da Fazenda São João Ltda, localizada no km 4 da rodovia RN-15, no município de Mossoró, RN, no período de 15 de setembro a 30 de novembro de 2000. Mossoró está situado na Latitude $5^{\circ}$ $11^{\prime} \mathrm{S}$, Longitude $37^{\circ} 20^{\prime} \mathrm{W}$, com altitude de $18 \mathrm{~m}$ e, segundo a classificação de Koppen, possui clima do tipo BSwh', isto é, seco, muito quente e com estação chuvosa no verão, atrasandose para o outono (Carmo Filho, 1989).

O solo é classificado como Argissolo Vermelho Amarelo, correspondendo ao Podzólico Vermelho Amarelo Eutrófico latossólico da antiga classificação, textura franco-argiloarenosa, fase caatinga hiperxerófila (SUDENE, 1968). A análise física encontra-se descrita na Tabela 1.

Tabela 1 Características físicas do solo da área experimental

\begin{tabular}{lrcc}
\hline \multirow{2}{*}{ Características Físicas } & \multicolumn{3}{c}{ Profundidade $(\mathrm{m})$} \\
\cline { 2 - 4 } & $0-0,15$ & $0,15-0,30$ & $0,30-0,45$ \\
\hline Granulometria $\left(\mathrm{g} \mathrm{kg}^{-1}\right)$ & 714 & 663 & 464 \\
Areia & 104 & 74 & 127 \\
Silte & 182 & 263 & 409 \\
Argila & 1,62 & 1,60 & 1,59 \\
Densidade global $\left(\mathrm{kg} \mathrm{dm}^{-3}\right)$ & 0,177 & 0,259 \\
Umidade de saturação $\left(\mathrm{g} \mathrm{g}^{-1}\right)$ & 0,177 & & \\
\hline
\end{tabular}

Os tratamentos estudados foram compostos da combinação de três fatores: salinidade da água de irrigação com 3 níveis $\left(\mathrm{S}_{1}-1,2 ; \mathrm{S}_{2}-2,5\right.$ e $\left.\mathrm{S}_{3}-4,5 \mathrm{dS} \mathrm{m}^{-1}\right)$, duas cultivares de melão $\left(\mathrm{C}_{1}\right.$ - Honey Dew cultivar Orange flesh e $\mathrm{C}_{2}$ - Cantaloupe híbrido Trusty) e duas freqüências de irrigação ( $\mathrm{F}_{1}$ - intervalos de um dia até os 30 dias após a semeadura (DAS) e duas vezes por

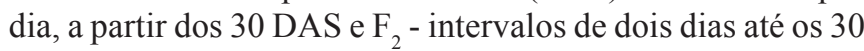
DAS e uma vez por dia, a partir dos $30 \mathrm{DAS}$ ). O delineamento estatístico adotado foi o de blocos inteiramente casualizados completos com quatro repetições e os fatores estudados foram arranjados no esquema fatorial de $3 \times 2 \times 2$.

A água de menor salinidade $\left(\mathrm{S}_{1}\right)$ se compunha da mistura de $70 \%$ da água proveniente de um poço artesiano profundo $\left(\mathrm{CE}-0,6 \mathrm{dS} \mathrm{m}^{-1}\right)$ e $30 \%$ de água de salinidade intermediária $\left(\mathrm{S}_{2}\right)$ proveniente de um poço do aqǘfero calcário $\left(\mathrm{CE}-2,5 \mathrm{dS} \mathrm{m}^{-1}\right)$, enquanto a água de maior salinidade $\left(\mathrm{S}_{3}\right)$ foi obtida acres- 
centando-se, na água $\mathrm{S}_{2} \mathrm{NaCl}$ em proporção de $1 \mathrm{~kg} \mathrm{~m}^{-3}$. A análise química das águas utilizadas no experimento está descrita na Tabela 2.

O plantio foi realizado no dia 15 de setembro de 2000 , utilizando-se o espaçamento de $2 \mathrm{~m}$ entre linhas de plantas e 0,60 m entre covas, com duas sementes por cova, correspondendo a uma população de plantio de 16.667 plantas ha-1.

O sistema de irrigação adotado foi o de gotejamento, com emissores do tipo autocompensante e vazão nominal de $3,75 \mathrm{~L} \mathrm{~h}^{-1}$, previamente avaliados no campo, sob condições normais de operação, apresentando um coeficiente de variação de vazão de $6,33 \%$ e vazão de $4,12 \mathrm{~L} \mathrm{~h}^{-1}$.

A irrigação foi realizada de modo a repor a evapotranspiração da cultura estimada para cada fase de desenvolvimento da planta, a partir da evapotranspiração de referência (ETo) pelo método de Penman-Monteith e coeficiente de cultura para a irrigação localizada, proposto pela FAO (Allen et al., 1998) acrescida de $10 \%$ e ajustadas com base no monitoramento da umidade do solo com o uso de tensiômetros instalados nas profundidades de 0,15; 0,30 e 0,45 $\mathrm{m}$ em raio de $0,15 \mathrm{~m}$ da planta e do gotejador, na região central de cada parcela experimental de dois blocos.

As adubações foram realizadas diariamente mediante fertigação, seguindo-se o cronograma da Fazenda São João, com base na necessidade da cultura, a partir do sétimo dia após a semeadura até, o enchimento dos frutos. As quantidades totais de $\mathrm{N}, \mathrm{P}_{2} \mathrm{O}_{5}$ e $\mathrm{K}_{2} \mathrm{O}$ utilizadas até o final do ciclo, foram 230; 248 e $423 \mathrm{~kg} \mathrm{ha}^{-1}$, respectivamente, utilizando-se nitrato de amônio, uréia, ácido fosfórico e nítrico e sulfato e nitrato de potássio.

Para estimar a variação da CE dentro do bulbo úmido pelo método de extratores de solução, instalou-se uma bateria com 9 extratores por tratamento a 0,$15 ; 0,30$ e $0,45 \mathrm{~m}$ de profundidade e a uma distância de $0 ; 0,20$ e 0,40 m da linha do gotejador. Para obtenção do extrato, no dia anterior ao da coleta era retirado o ar de dentro dos extratores, introduzindo-se uma agulha com seringa de $60 \mathrm{~mL}$ na borracha especial de vedação, criando uma sucção interna de aproximadamente $30 \mathrm{kPa}$. $\mathrm{O}$ extrato (solução do solo) foi coletado três dias consecutivos por semana, ao longo do ciclo da cultura, e as amostras conduzidas ao Laboratório de Irrigação e Salinidade da Escola Superior de Agricultura de Mossoró, para se efetuar as leituras de condutividade elétrica. Após a terceira leitura semanal, os extratores eram preenchidos com água destilada, passando a funcionar como tensiômetros, nos quais se realizavam leituras três vezes por dia, às 6:00, 13:00 e 17:00 h, até os 72 dias após o plantio.

A determinação da salinidade do solo pelo método convencional, foi feita para as camadas $0-0,15,0,15-0,30$ e 0,30-0,45 m, no início (21 DAS), aos 45 DAS e no final do ciclo (70 DAS). As amostras de solo em cada parcela experimental, se constituíram de amostras compostas de 3 pontos a $15 \mathrm{~cm}$ do gotejador, em forma de triângulo.

A salinidade do solo (condutividade elétrica do extrato de saturação - $\mathrm{CE}_{\mathrm{es}}$ ), a exemplo de Rhoades \& Miyamoto (1990) e Medeiros (1998) foi estimada a partir da $\mathrm{CE}_{1: 2}$ (solo-água) mediante uma equação de regressão, determinada a partir de medidas dessas CE's obtidas em parte das amostras representando todas as épocas e profundidades de amostragem e tratamentos

As equações de regressão adotadas para obtenção da condutividade elétrica do extrato de saturação, foram CEes = $7,19\left(\mathrm{CE}_{1 \cdot 2}\right)+0,09\left(\mathrm{r}^{2}=0,96\right)$ para as camadas de $0-0,15$ e 0,15 $0,30 \mathrm{~m}$ e CEes $=4,59\left(\mathrm{CE}_{1: 2}\right)+0,54\left(\mathrm{r}^{2}=0,97\right)$ para a camada $0,30-0,45 \mathrm{~m}$.

\section{RESULTADOS E DISCUSSÃO}

\section{Evolução da salinidade na zona radicular do meloeiro}

A evolução da salinidade do solo em diferentes camadas, durante o ciclo do melão, para as diferentes salinidades de água de irrigação, é mostrada na Figura 1. Maiores valores de salinidade foram observados para as camadas superficiais, ao longo do ciclo. Nota-se ainda que, a partir dos 21 DAS, para todas as amostras efetuadas, a salinidade do solo nas parcelas irrigadas com água de maior salinidade foi superior à da água menos salina, em todas as camadas de solo. Considerando-se que em diferentes tratamentos se aplicaram as lâminas de águas semelhantes, tal fato pode ser explicado pela maior quantidade de sais adicionados ao solo, quando irrigado com salinidade elevada $\left(\mathrm{CE}_{\mathrm{a}}-4,5 \mathrm{dS} \mathrm{\textrm {m } ^ { - 1 }}\right)$.

No geral, os tratamentos proporcionaram curvas de salinização aproximadamente paralelas entre as camadas de solo, com um aumento entre 21 e 45 dias e redução para o final do ciclo. A redução nos valores de salinidade do solo, em cada camada, pode ser atribuída à posição do bulbo úmido em que foi monitorada, aproximadamente $0,15 \mathrm{~m}$ do seu centro, região esta onde ocorre lixiviação, seja na vertical como na horizontal (Medeiros, 1998), levando os sais para a periferia mais distante, ou seja, fora da área onde ocorreu a monitoração da salinidade.

Um outro fator que ocasionou esta redução foi, sem dúvida, a diminuição na evapotranspiração, devido à perda da folhagem da cultura na fase final do ciclo, sendo a lâmina de água diária superestimada, ocasionando maior lixiviação dos sais para as camadas mais profundas; além disso, a maior área coberta pelo bulbo no final do ciclo fez com que o ponto de amostragem ficasse na região de maior lixiviação, como já comentado. Tal fato está de acordo com Medeiros (1998) ao afirmar que a principal influência da irrigação com água salina é produzir

Tabela 2. Análise das águas utilizadas na irrigação

\begin{tabular}{|c|c|c|c|c|c|c|c|c|c|}
\hline \multirow{2}{*}{ Água } & \multirow{2}{*}{$\mathrm{CE}\left(\mathrm{dS} \mathrm{m}{ }^{-1}\right)$} & \multirow{2}{*}{$\mathrm{pH}$} & $\mathrm{Ca}$ & $\mathrm{Mg}$ & $\mathrm{K}$ & $\mathrm{Na}$ & $\mathrm{Cl}$ & $\mathrm{HCO}_{3}$ & \multirow{2}{*}{$\operatorname{RAS}^{*}\left(\mathrm{mmol} \mathrm{L}^{-1}\right)^{0,5}$} \\
\hline & & & \multicolumn{6}{|c|}{$\mathrm{mmol}_{\mathrm{c}} \mathrm{L}^{-1}$} & \\
\hline $\mathrm{S}_{1}$ & 1,20 & 6,95 & 5,3 & 2,61 & 0,49 & 2,31 & 4,66 & 4,61 & 1,64 \\
\hline $\mathrm{S}_{3}$ & 4,50 & 6,80 & 9,9 & 5,20 & 0,13 & 29,77 & 35,49 & 6,50 & 15,32 \\
\hline
\end{tabular}

"Relação de Adsorção de Sódio 

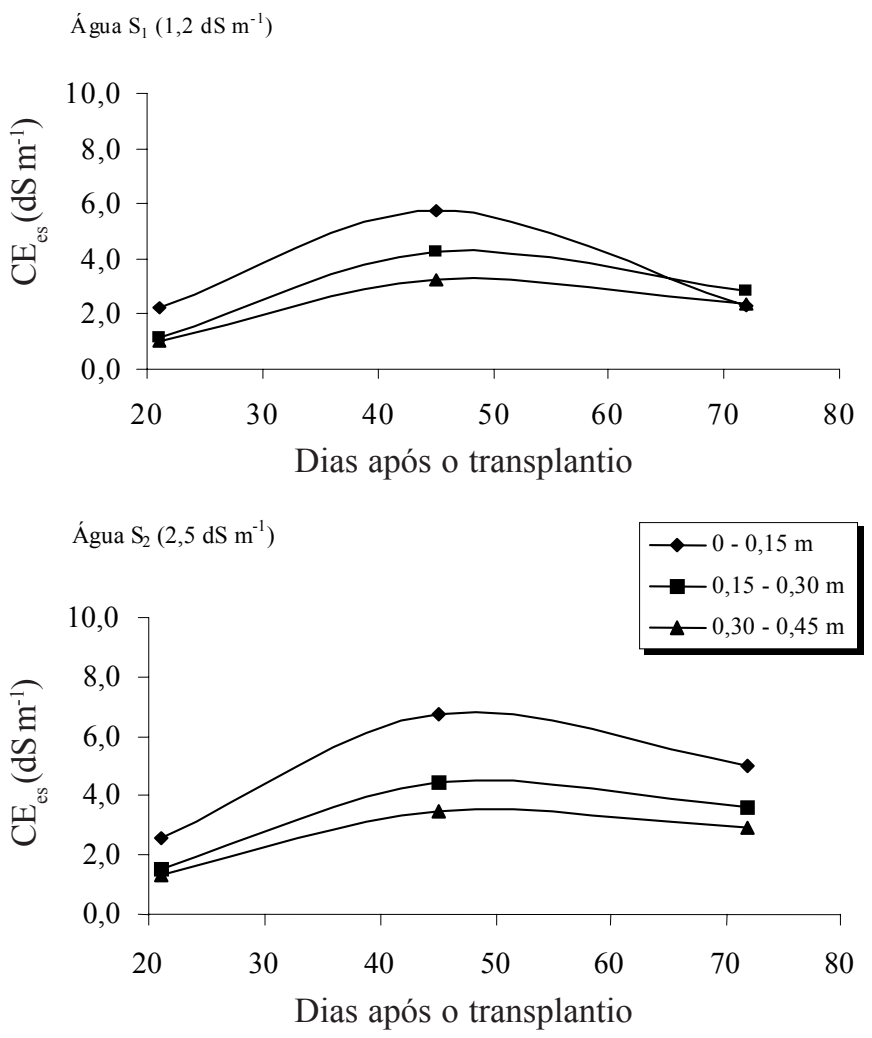

Água $\mathrm{S}_{3}\left(4,5 \mathrm{dS} \mathrm{m}^{-1}\right)$



Figura 1. Evolução da salinidade do solo $\left(\mathrm{CE}_{\mathrm{es}}\right)$ ao longo do ciclo do meloeiro para diferentes camadas de solo e salinidade da água de irrigação

valores de salinidade do solo maiores a partir do início do cultivo. Gurgel et al. (2003) trabalhando com evolução da salinidade em solo similar na região de Mossoró, RN, também verificaram de forma semelhante o aumento da salinidade ao longo do ciclo do meloeiro.

Na Tabela 3 estão apresentados resumo da análise da variância e valores médios da salinidade do solo ao longo do tempo, para as profundidades de $0-0,15 ; 0,15-0,30$ e $0,30-0,45$ $\mathrm{m}$, aos 21, 45 e 72 dias após a semeadura. Verifica-se que a salinidade da água afetou, de forma significativa $(\mathrm{p}<0,05)$ a salinidade do solo, exceto para as camadas $0,30-0,45 \mathrm{~m}$ aos 21 DAS e 0,15-0,30 m aos 45 e 72 DAS, com aumento proporcional à salinidade da água de irrigação.

Em relação à freqüência de irrigação, observou-se tendência de maior acúmulo de sais nas irrigações com menor freqüência $\left(\mathrm{F}_{2}\right)$ no final do ciclo, sobretudo na camada superficial devido, provavelmente, ao fato das irrigações mais freqüentes aumentarem a evaporação na superfície do solo, resultando em uma evapotranspiração maior e em conseqüência, maior volume de água aplicado por irrigação, culminando em um aumento global na salinidade do solo. Conforme Bernstein \& François (1973) sob condições de equilíbrio o aumento da freqüência de irrigação resulta em uma mudança para cima do pico de salinidade no perfil de distribuição de sais, fazendo com que aumente a concentração média de sais na porção superior da zona radicular. Com irrigação menos freqüente, as lâminas de água aplicadas por evento de irrigação são maiores, aumentando o movimento lateral e vertical da água.

Em geral, a salinidade média do solo, para todos os níveis de salinidade de água diminuiu com a profundidade. Nota-se que a irrigação com água $S_{1}$ resultou numa salinidade aos 21 DAS, na camada $0-0,15 \mathrm{~m}$, de $2,24 \mathrm{dS} \mathrm{m}^{-1}$, estando no limite de tolerância de salinidade a cultura do melão, que é de $2,2 \mathrm{dS} \mathrm{m}^{-1}$, conforme Pizarro (1978).

Santos (1997), estudando os efeitos de níveis de salinidade de água e de lâminas de irrigação na evolução da salinidade do solo, concluiu que houve acúmulos de sais no solo, nas três profundidades estudadas, sendo diretamente proporcionais aos níveis de água de irrigação. Medeiros (1998), Silveira (1999) e Blanco \& Folegatti (2002), demonstraram que o acúmulo de sais é maior na camada superficial do solo, quando são feitas irrigações localizadas durante períodos curtos.

Como se previa, os valores de salinidade do solo foram mais altos que a salinidade das águas, sobretudo para as duas águas menos salinas, pelo fato dos adubos aplicados via fertigação terem contribuído para elevar a salinidade da água, além da fração de lixiviação utilizada ser baixa (projetada $0,10)$. Neste caso, o excesso de água "apenas" proporcionou aumento do diâmetro do bulbo molhado, uma vez que o solo, a partir dos 0,4 $\mathrm{m}$ de profundidade, apresenta um horizonte com baixa condutividade hidráulica. De acordo com Keller (1966) o acúmulo de sais na zona radicular das culturas irrigadas depende da concentração de sais na água, do método de aplicação, da precipitação pluviométrica e das características do solo.

Fertilizantes em dosagens maiores aplicados entre os 35 e 45 DAS, aumentaram não apenas a salinidade da água de irrigação mas, também, a própria salinidade do solo, fato este que pode ser, em parte, responsável pela salinidade máxima observada aos 45 DAS. Os valores dos coeficientes lineares das equações apresentadas na Figura 2 refletem a salinidade proveniente dos adubos, pois na $\mathrm{CE}$ da água, quando foi feita a análise de regressão, não se somou a advinda dos adubos, que atingiu valores maiores que $0,6 \mathrm{dS} \mathrm{m}^{-1}$; além disso, refletem a possível precipitação dos sais $\left(\mathrm{CaCO}_{3}\right)$ haja vista a elevada concentração de $\mathrm{Ca}^{++}$e $\mathrm{HCO}_{3}^{-}$nas águas $\mathrm{S}_{2}$ e $\mathrm{S}_{3}$.

\section{Salinidade no bulbo úmido, medida por extratores}

$\mathrm{Na}$ Tabela 4 estão apresentadas as médias da condutividade elétrica para a camada de $0-0,45 \mathrm{~m}$, medidas por extratores a 0; 0,20 e 0,40 m do gotejador para as diferentes salinidades de água de irrigação e épocas. Maiores valores de salinidade foram observados próximos aos gotejadores e, a medida em que o tempo foi passando, a salinidade média no perfil cresceu para 
Tabela 3. Resumo da ANAVA e médias da salinidade do solo $\left(\mathrm{CE}_{\mathrm{es}}\right)$ ao longo do tempo nas camadas de $0-0,15 ; 0,15-0,30$ e $0,30-0,45 \mathrm{~m}$, para as salinidades de água, freqüência de irrigação e cultivar no cultivo do meloeiro

\begin{tabular}{|c|c|c|c|c|c|c|c|c|c|}
\hline \multirow{2}{*}{ Fator } & \multicolumn{3}{|c|}{$21 \mathrm{DAS}$} & \multicolumn{3}{|c|}{45 DAS } & \multicolumn{3}{|c|}{72 DAS } \\
\hline & $0-15$ & $15-30$ & $30-45$ & $0-15$ & $15-30$ & $30-45$ & $0-15$ & $15-30$ & $30-45$ \\
\hline & \multicolumn{9}{|c|}{ Estatística F } \\
\hline Salinidade & $4,06^{*}$ & $5,90 * *$ & $2,00^{\mathrm{ns}}$ & $3,68^{*}$ & $2,98^{\mathrm{ns}}$ & $3,79^{*}$ & $12,15^{* *}$ & $2,36^{\mathrm{ns}}$ & $3,99 *$ \\
\hline Linear & $8,12 * *$ & $11,45^{*}$ & $3,98^{\text {ns }}$ & $7,34 * *$ & $5,17 *$ & $7,23 *$ & $23,98 * *$ & $4,7^{*}$ & $7,97 * *$ \\
\hline Freqüência & $2,17^{\mathrm{ns}}$ & $2,74^{\mathrm{ns}}$ & $1,08^{\mathrm{ns}}$ & $1,81^{\mathrm{ns}}$ & $2,09^{\mathrm{ns}}$ & $0,25^{\mathrm{ns}}$ & $0,14^{\mathrm{ns}}$ & $0,20^{\mathrm{ns}}$ & $0,16^{\mathrm{ns}}$ \\
\hline Cultivar & $0,88^{\text {ns }}$ & $0,89^{\mathrm{ns}}$ & $4,59^{\mathrm{ns}}$ & $1,10^{\mathrm{ns}}$ & $0,26^{\mathrm{ns}}$ & $1,39^{\mathrm{ns}}$ & $4,39^{\mathrm{ns}}$ & $5,52^{\mathrm{ns}}$ & $0,48^{\text {ns }}$ \\
\hline \multirow[t]{2}{*}{ QM Resíduo } & 1,254 & 0,164 & 0,374 & 4,07 & 3,701 & 0,991 & 4,709 & 4,34 & 0,9039 \\
\hline & \multicolumn{9}{|c|}{ Salinidade Média do Solo $\left(\mathrm{dS} \mathrm{m}^{-1}\right)$} \\
\hline \multicolumn{10}{|c|}{ Salinidade da água (dS m $\left.{ }^{-1}\right)$} \\
\hline $\mathrm{S}_{1}=1,2$ & 2,24 & 1,14 & 1,03 & 5,75 & 4,26 & 3,21 & 2,34 & 2,86 & 2,38 \\
\hline $\mathrm{S}_{2}=2,5$ & 2,58 & 1,52 & 1,30 & 6,75 & 4,71 & 3,46 & 5,00 & 3,61 & 2,91 \\
\hline $\mathrm{S}_{3}=4,5$ & 3,22 & 1,83 & 1,64 & 8,46 & 6,48 & 4,50 & 7,70 & 5,08 & 7,71 \\
\hline $\mathrm{S}_{3} / \mathrm{S}_{1}$ & 1,44 & 1,61 & 1,59 & 1,47 & 1,52 & 1,40 & 3,29 & 1,78 & 3,24 \\
\hline \multicolumn{10}{|c|}{ Freqüência de Irrigação } \\
\hline $\mathrm{F}_{1}$ & 2,66 & 1,50 & 1,21 & 6,77 & 4,55 & 3,34 & 5,58 & 4,26 & 3,18 \\
\hline $\mathrm{F}_{2}$ & 2,71 & 1,50 & 1,43 & 7,19 & 5,75 & 4,09 & 4,44 & 3,43 & 2,82 \\
\hline \multicolumn{10}{|l|}{ Cultivar } \\
\hline $\mathrm{C}_{1}$ & 2,60 & 1,24 & 3,09 & 6,93 & 4,78 & 3,96 & 5,43 & 3,87 & 2,92 \\
\hline $\mathrm{C}_{2}$ & 2,77 & 1,75 & 2,92 & 7,04 & 5,51 & 3,47 & 4,59 & 3,82 & 3,09 \\
\hline
\end{tabular}

ns, * **, não significativo, significativo em nível de 0,05 e 0,01 de probabilidade pelo teste $\mathrm{F}$, respectivamente.



CE da Ägua de Irrigação $\left(\mathrm{dS} \mathrm{m}^{-1}\right)$

Figura 2. Relação entre a salinidade do solo, média para a camada 0 a $45 \mathrm{~cm}$, e salinidade da água de irrigação para diferentes épocas de amostragem

a periferia $(0,40 \mathrm{~m}$ do gotejador), porém ficando ainda inferior ao valor obtido próximo do gotejador.

A salinidade do solo na camada de $0-0,45 \mathrm{~m}$ aumentou linearmente com a elevação da salinidade água de irrigação ao longo do ciclo da cultura do melão (Figura 3), com redução no final do ciclo (72 dias). Comportamento semelhante foi observado na avaliação da salinidade do solo, medida através do método padrão (Figura 2).

Na Figura 4 estão apresentadas as curvas de evolução da salinidade do solo expressa em condutividade elétrica determinada por meio de análise de solo na camada 0 - 0,45 m, (método padrão) e a obtida por extratores em campo, localizadas a 0 e $0,20 \mathrm{~m}$ do gotejador para diferentes tratamentos. Observa- se semelhança entre as curvas da salinidade do solo, pelo método padrão e pelos extratores em campo, sendo a última superior em todas os níveis de salinidade da água, o que já era esperado, pelo fato do extrator retirar a solução quando o solo está próximo à capacidade de campo ou abaixo deste ponto de umidade $\left(\Psi_{\mathrm{m}}<-10 \mathrm{kPa}\right)$ sendo o teor de umidade no solo menor que no ponto de saturação, fazendo com que uma diluição dos sais presentes na solução, diminuindo a concentração salina e, conseqüentemente, a condutividade elétrica; outrossim, a

Tabela 4. Valores médios da condutividade elétrica na camada de $0-0,45 \mathrm{~cm}$, medidos por extratores a $0 ; 0,20$ e $0,40 \mathrm{~m}$ do gotejador para as três épocas de amostragem

\begin{tabular}{|c|c|c|c|c|}
\hline \multirow{2}{*}{$\begin{array}{l}\text { Salinidade da Água } \\
\left(\mathrm{dS} \mathrm{m}^{-1}\right)\end{array}$} & \multicolumn{4}{|c|}{ Distância do gotejador (m) } \\
\hline & 0 & 0,20 & 0,40 & Média \\
\hline \multicolumn{5}{|l|}{28 DAS } \\
\hline 1,2 & 2,94 & 2,10 & 1,53 & 2,19 \\
\hline 2,5 & 3,73 & 3,35 & 2,61 & 3,23 \\
\hline 4,5 & 6,19 & 4,60 & 3,74 & 4,84 \\
\hline Média & 4,29 & 3,35 & 2,63 & \\
\hline \multicolumn{5}{|l|}{45 DAS } \\
\hline 1,2 & 4,61 & 4,93 & 3,66 & 4,42 \\
\hline 2,5 & 6,76 & 5,89 & 5,17 & 5,94 \\
\hline 4,5 & 9,37 & 9,37 & 3,74 & 7,49 \\
\hline Média & 6,91 & 6,73 & 4,19 & \\
\hline \multicolumn{5}{|l|}{72 DAS } \\
\hline 1,2 & 5,78 & 3,83 & 2,80 & 4,14 \\
\hline 2,5 & 4,76 & 5,16 & 3,67 & 4,53 \\
\hline 4,5 & 7,22 & 7,44 & 8,23 & 7,63 \\
\hline Média & 5,92 & 5,48 & 4,90 & \\
\hline
\end{tabular}




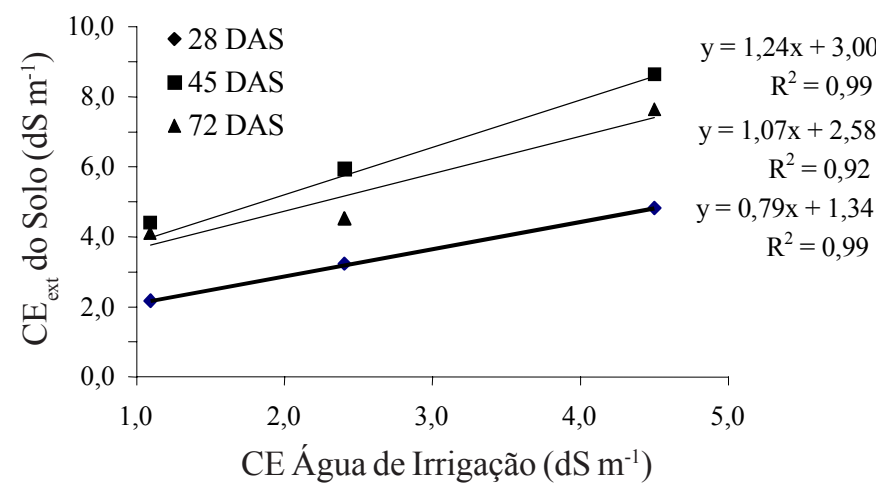

Figura 3 Relação entre a salinidade do solo medida por extratores ao longo do ciclo da cultura do melão, na camada de $0-0,45$ $\mathrm{m}$, e a salinidade da água de irrigação

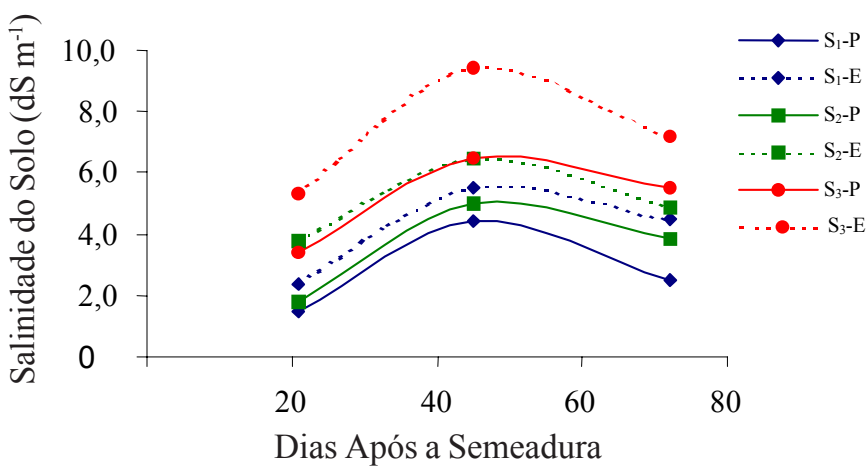

Figura 4. Evolução da salinidade do solo na camada de 0 - 0,45 m observado pelo método padrão $(\mathrm{P})$ e por extratores de solução em campo (E) para as diferentes águas de irrigação (S)

salinidade medida utilizando-se os extratores, é pontual (apenas ao redor da cápsula), enquanto no método padrão a amostragem representa a média de uma camada de solo.

Na Tabela 5 tem-se o valor médio da umidade no momento da extração da solução no solo $\left(\theta_{\text {as }}\right)$, da umidade de saturação do solo $\left(\theta_{\mathrm{ss}}\right)$ e da relação entre $\theta_{\text {as }}$ e $\theta_{\text {ss }}$, para os diferentes níveis de salinidade de água de irrigação, aos 21, 45 e 72 DAS. Vê-se que a média da umidade de saturação do solo é aproximadamente 1,67 vez maior que a umidade atual do solo, ou seja, $\theta_{\mathrm{ss}}=1,67 \times \theta_{\text {as }}$ ou $\theta_{\text {as }} / \theta_{\text {ss }}=0,60$. Deste modo, a condutividade elétrica medida nos extratores é mais ou menos igual a 1,67 vez a condutividade elétrica do extrato de saturação estimado, ou seja, $\mathrm{CE}_{\mathrm{ext}}=1,67 \mathrm{CE}_{\mathrm{es}}$. De acordo com Ayers \& Westcot (1991) o solo de textura média tem umidade à capacidade de campo quase igual à metade da condição de saturação $\left(\theta_{\mathrm{cc}}=0,5 \times \theta_{\mathrm{ss}}\right)$; assim, a relação entre a umidade atual do solo e a capacidade de campo observada no presente estudo é coerente, uma vez que o solo estudado apresenta textura arenosa para a camada de 0 a $0,30 \mathrm{~m}$ e a umidade no solo foi mantida próxima à capacidade de campo, mediante irrigações freqüentes.

A razão entre $\theta_{\text {as }}$ e $\theta_{\mathrm{ss}}$ aproxima-se do valor do coeficiente angular da reta encontrada na relação entre a $\mathrm{CE}_{\mathrm{ext}}$ e a $\mathrm{CE}_{\mathrm{es}}$ (Figura 5) que foi de 0,70. Silva et al. (2000), também verificaram
Tabela 5. Valores médios da umidade atual do solo $\left(\theta_{\text {as }}\right)$, de umidade de saturação do solo $\left(\theta_{\mathrm{ss}}\right)$ e da relação $\theta_{\mathrm{as}} / \theta_{\mathrm{ss}}$ para os diferentes níveis de salinidade de água de irrigação, aos 21 , 45 e 72 dias após a semeadura (DAS)

\begin{tabular}{lcccc}
\hline \multirow{2}{*}{ Parâmetros } & \multicolumn{4}{c}{ Salinidade de Água - $\mathrm{dS} \mathrm{m}^{-1}$} \\
\cline { 2 - 5 } & 1,2 & 2,5 & 4,5 & Média \\
\hline A. 21 DAS & & & & \\
Umidade atual $\left(\theta_{\mathrm{as}}\right)-\%$ & 12,71 & 12,08 & 12,20 & 12,33 \\
Umidade de saturação $\left(\theta_{\mathrm{ss}}\right)-\%$ & 23,88 & 23,78 & 21,93 & 23,19 \\
Relação $\theta_{\mathrm{as}} / \theta_{\mathrm{ss}}$ & 0,55 & 0,52 & 0,53 & 0,53
\end{tabular}

\section{B. 45 DAS}

Umidade atual $\left(\theta_{\mathrm{as}}\right)-\% \quad 12,19 \quad 12,54 \quad 12,71 \quad 12,48$

Umidade de saturação $\left(\theta_{\mathrm{ss}}\right)-\% \quad 20,56 \quad 19,23 \quad 21,44 \quad 20,41$

$\begin{array}{lllll}\text { Relação } \theta_{\mathrm{a}} / \theta_{\mathrm{ss}} & 0,59 & 0,65 & 0,59 & 0,61\end{array}$

\section{72 DAS}

Umidade atual $\left(\theta_{\mathrm{a}} \mathrm{s}\right)-\% \quad 10,68 \quad 12,63 \quad 12,60 \quad 11,94$

Umidade de saturação $\left(\theta_{\mathrm{ss}}\right)-\% \quad 16,60 \quad 19,98 \quad 19,59 \quad 18,72$

$\begin{array}{lllll}\text { Relação } \theta_{\mathrm{a}} / \theta_{\mathrm{ss}} & 0,67 & 0,63 & 0,66 & 0,65\end{array}$

Relação $\theta_{\mathrm{a}} / \theta_{\mathrm{ss}}$ média $\quad 0,60$

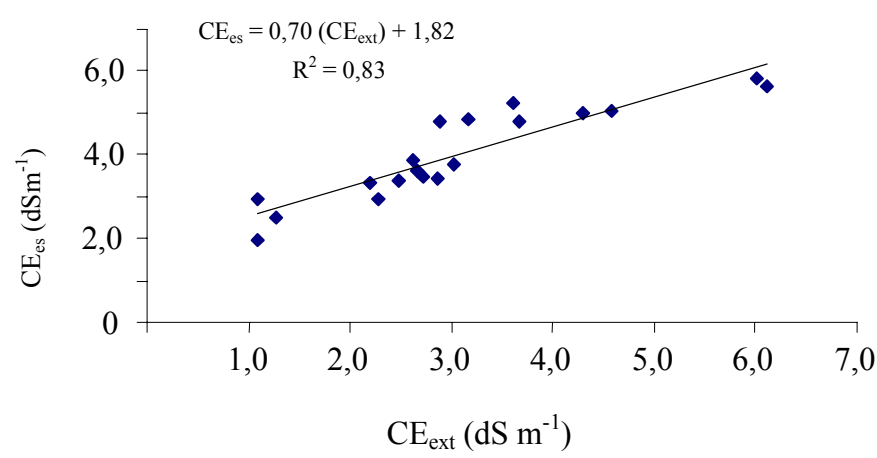

Figura 5. Relação entre a condutividade elétrica do extrato de saturação do solo $\left(\mathrm{CE}_{\mathrm{es}}\right)$ e a obtida por extratores em campo $\left(\mathrm{CE}_{\mathrm{ext}}\right)$

que a CE obtida por extratores corrigidos para umidade de saturação, equivale à $\mathrm{CE}$ do extrato de saturação medida pelo método padrão.

\section{CONCLUSÕES}

1. A salinidade do solo tende a diminuir a partir da metade do ciclo cultural do meloeiro.

2. Evolução da salinidade do solo é proporcional à concentração de sais da água de irrigação, independente da freqüência de irrigação.

3. A irrigação com água de menor nível de salinidade resulta numa salinidade final na camada de $0-0,15 \mathrm{~m}$, próxima ao limite de tolerância da cultura do meloeiro à salinidade.

4. A condutividade elétrica do extrato de saturação do solo é igual 0,70 vezes a condutividade elétrica da solução obtida com extrator de cápsula porosa (CEes $=0,7$ x CEext $+1,82)$ aproximando-se da razão entre a umidade de saturação e a atual do solo. 


\section{LITERATURA CITADA}

Allen, R.G.; Pereira, L.S.; Raes, D.; Smith, M. Crop evapotranspiration: Guidelines for computing crop water requirements. Rome: Food and Agriculture Organization of the United Nations, 1998. 300p. FAO. Irrigation and Drainage, Paper 56

Ayers, R.S.; Westcot, D. W. Qualidade de água na agricultura.. Campina Grande: UFPB, 1991. 218p. FAO. Estudos de Irrigação e Drenagem, 29

Bernstein, L.; François, L.E. Comparisons of drip, furrow and sprinkler irrigation. Soil Science, Baltimor, v.115, n.1, p.7386, 1973.

Blanco, F.F.; Folegatti, M.V. Salt accumulation and distribution in a greenhouse soil as affected by salinity of irrigation water and leaching management. Revista Brasileira de Engenharia Agrícola e Ambiental, Campina Grande, v.6, n.3, p.414-419, 2002.

Carmo Filho, F. Mossoró: Um município do semi-árido: características climáticas e aspectos florestais. 2.ed. Mossoró: ESAM, 1989. 62 p. Coleção Mossoroense, 672, série B.

Dias, N.S.; Gheyi, H.R.; Duarte, S.N. Prevenção, manejo e recuperação dos solos afetados por sais. Piracicaba: ESALQ, Departamento de Engenharia Rural, 2003. 118p. Série Didática, 13

DNOCS - Departamento de Obras Contra as Secas. Situação das áreas em 30/04/1991. Fortaleza: Grupos de Coordenação Executiva das Operações Agrícolas (GOA), 1991. sp

Gurgel, M.T.; Medeiros, J.F.; Nobre, R.G.; Cardoso Neto, F.C.; Silva, F.V. Evolução da salinidade no solo sob cultivo de melão irrigado com águas de diferentes salinidade. Revista de Biologia e Ciência da Terra, Belo Horizonte, v.3, n.2, p.113, 2003.

Keller, J. Effect of water application on leaching. Soil Science, Baltimor, v.102, p. 107-114, 1966.

Medeiros, J.F de. Manejo da água de irrigação salina em estufa cultivada com pimentão. Piracicaba: ESALQ, 1998. 152p. Tese Doutorado.

Medeiros, J.F. de.; Gheyi, H.R. Manejo do sistema solo-águaplanta em solos afetados por sais. In: Gheyi, H.R.; Queiroz, J.E.; Medeiros, J.F. de (eds.). Manejo e controle da salinidade na agricultura irrigada. Campina Grande: UFPB/SBEA, 1997. cap. 8, p. 239-284.
Medeiros, J. F de.; Lisboa, R. A.; Oliveira, M.; Silva Júnior, M. J.; Alves, L. P. Caracterização das águas subterrâneas usadas para irrigação na área produtora de melão da Chapada do Apodi. Revista Brasileira de Engenharia Agrícola e Ambiental, Campina Grande, v.7, n.3, p.469-472, 2003.

Negreiros, M.Z.; Medeiros, J.F.; Sales Júnior, R.; Menezes, J.B. Cultivo de melão no pólo agrícola Rio Grande do Norte/ Ceará. Horticultura Brasileira, Brasília, v.21, n.3, p.1-1, 2003.

Oliveira, M. Gênese, classificação e extensão de solos afetados por sais. In: Gheyi, H.R.; Queiroz, J.E.; Medeiros, J.F. de (eds.). Manejo e controle da salinidade na agricultura irrigada. Campina Grande: UFPB/SBEA, 1997. cap.1, p.1-35.

Pizarro, F. Drenaje agrícola y recuperación de suelos salinos. Madrid: Ed. Agrícola Española, 1978. 521p.

Rhoades, J.D. Electrical conductivity methods for measuring and mapping soil salinity. Advances in Agronomy, San Diego, v.49, p.201-251, 1994.

Rhoades, J.D.; Miyamoto, S. Testing soils for salinity and sodicity. In: Westerman, R.L. (ed.). Soil testing and plant analysis. Madison: Soil Science Society of America, 1990. cap. 12, p.299-336. Book Series, 3

Richards, L.A. Diagnosis and improvement of saline and alkali soils. Washington: United States Department of Agriculture, 1954. 160p. Agriculture Handbook, 60.

Santos, J.G.R. dos. Desenvolvimento e produção da bananeira nanica sob diferentes níveis de salinidade e lâminas de água. Campina Grande: UFPB, 1997. 173p. Tese Doutorado

Silva, E.F.F. Manejo da fertirrigação e controle da salinidade na cultura do pimentão utilizando extratores de solução do solo. Piracicaba: ESALQ, 2002. 136p. Tese Doutorado

Silva, E.F.F.; Anti, G..R.; Carmello, Q.A.C.; Duarte, S.N. Extratores de cápsulas porosas e o monitoramento da condutividade elétrica e do teor de potássio na solução de um solo. Scientia Agrícola, Piracicaba, v.57, n.4, p.785-789, 2000.

Silveira, C.C da. Avaliação da salinidade dentro do bulbo úmido na cultura do melão. Mossoró: ESAM, 1999. 34p. Monografia Graduação

SUDENE. Superintendência de Desenvolvimento do Nordeste. Divisão Agrológica. Mapa Exploratório- Reconhecimento de solos do Estado do Rio Grande do Norte. Map ed. 75 x 85 $\mathrm{cm}$, Escala 1:500.000, 1968. Relatório anual. 